\title{
The Comprehensive Evaluation for the Social Benefits of the Natural Gas CCHP Project based on the AHP-GCDM model
}

\author{
Huiru Zhao, Zhao Ma and Nana Li \\ School of Economics and Management, North China Electric Power University \\ E-mail of Nana Li: nancyli1007@163.com
}

\begin{abstract}
In order to promote the development of natural gas Combined Cooling Heating and Power (CCHP) project in China, it is critical for us to comprehensively evaluate the social benefits. This paper establishes a comprehensive evaluation index system which contains the natural environmental benefit, and the social economy benefits. Moreover, a comprehensive evaluation model based on AHP-formula method and GCDM is proposed to evaluate the social benefits of the natural gas CCHP project. At last, an empirical analysis of a project in city A is presented, which shows that the social benefits of this project is "very good", and the feasibility of this model is proved.
\end{abstract}

Keywords: Combined Cooling Heating and Power, social benefits, AHP, Formula method, GCDM, comprehensive evaluation

\section{Introduction}

On the basis of energy cascade utilization, the natural gas CCHP project can integrate the cooling, heating and power generation processes. Facing the serious situation of energy supply and environment, the natural gas CCHP project can improve the utility efficiency of primary energy and cut down the emission of greenhouse gas. However, due to the lack of investment, at present, CCHP projects have not been used widely in China. On one hand, the policies and regulations on energy and environment are still deficient in China, as well as the encourage policies on environmental protection. On the other hand, the feed-in tariff of the CHPC plants has no advantage comparing with the regular energy. What's more, the price of natural gas fluctuates severely. Above all, it is indispensable to evaluate and analyze the social benefits from a comprehensive perspective, so as to improve the development of the natural gas CCHP project in China.

Currently, the research about the natural gas CCHP project mainly focus on the operation optimizations of system and economic. The study on the system optimization includes: the optimization of the principal devices in the CCHP system [1, 2], the optimal running states of the CCHP system under various external conditions [3, 4], the optimal allocation of the CCHP system [5, 6], the optimization of running mode for the CCHP system [7, 8], and so on. For the aspect of economic operation, the research mainly focuses on the optimization of economical efficiency. Literature [9] established an objective function for minimizing the annual costs, and proposed a best operation strategy.

However, it is still scarce that study on the evaluation of social benefits for the natural gas CCHP project. Moreover, the short of research on the evaluation standard and indicators of the social benefits hinders the application and popularization of the project. Therefore, in order to promote the application and fully exerts the comprehensive benefits of the natural gas CCHP projects, it is vital to build scientifically the evaluation index system and an evaluation model for the comprehensive benefits of the project. This paper establishes a comprehensive evaluation index system which contains two aspects: the natural environmental benefits and society economic benefits. Meanwhile, a 
comprehensive model is established based on AHP-Formula method and GCDM model to evaluate the social benefits of the CCHP project.

The remainder of the paper is organized as follows: Section 2 establishes the evaluation index system for the comprehensive social benefits. In the Section 3, the evaluation model is established based on the analysis of the AHP-Formula method and GCDM model. An empirical analysis is proposed in the Section 4. At last, the conclusions are drawn.

\section{The Evaluation Index System of the Natural Gas CCHP Project Social Benefits}

The social benefits of natural gas CCHP project are mainly manifested in two aspects: the natural environmental benefits and the social economy benefits $[10,11]$. Therefore, the evaluation index system for evaluating the social benefits of CCHP project is established in this part. The specific indicators and their meanings are shown as follows:

2.1 The natural environmental benefits

The environmental benefits evaluation of gas CCHP project mainly covers the energy saving and the emission reduction.

(1) Resource saving benefit

Compared with the coal energy, the utilization efficiency of natural gas is much higher. Namely, natural gas will produce more energy in the same condition. The extensive use of the natural gas CCHP project can effectively save coal and other fossil energy, which can save more resources.

(2) Pollutant emission reduction benefits

Pollutant emission is an important aspect of energy systems which affects natural environment seriously. Compared to the traditional way of coal-fired energy supply, natural gas CCHP project will greatly reduce the emissions of $\mathrm{CO}_{2}, \mathrm{SO}_{2}, \mathrm{NO}_{2}$ and other harmful gases, which would be helpful to improve the environment and alleviate the greenhouse effect [12].

(3) Resources recycling benefits

The natural gas CCHP energy supply system can provide users with cold energy and heat energy by recycling waste gas from the turbine generation system, which would improve the energy efficiency and reduce the pollution of the whole system [13].

2.2 The social economy benefits

The benefits of the social economy are the economic impact driven by the natural gas CCHP project from a macroeconomic perspective.

(1) Power grid operation efficiency benefits

The natural gas CCHP project owns strong peak shaving ability, which can meet the needs of the peak shaving. Meanwhile, the project also has the peaking capacity for gas pipeline network, which can realize the economic operation and ensure the safety for gas pipeline network [14].

(2) The land use benefits

The natural gas CCHP project belongs to the distributed energy, which is generally arranged in the vicinity of the users. In this way, it can not only make full use of the idle land resources near the users, but also can attract other users close to the energy supply system, which increases the value of the land accordingly.

(3) Industry development benefits

The natural gas CCHP project has a special significance for the long-term development of the electricity industry. Because of the inherent advantages above, the natural gas CCHP projects are often established in the heart areas of energy consumption, which will reduce the loss of the transmission lines and the consequent land, etc. Therefore, for electricity industry, natural gas CCHP projects can improve their profit and the 
development of the power industry.

(4) Social employment benefits

As we all know, the project design, civil engineering construction, machinery manufacturing, equipment maintenance and other industries are involved in the process of construction and operation of CCHP [15]. All these relative industries would increase employment opportunities to the society to some extent.

\section{Comprehensive Evaluation Model based on AHP and Improved GCDM Model}

\subsection{Analytic Hierarchy Process}

AHP is an applied multi-objective decision method which combines the qualitative analysis and quantitative analysis, can solve complex system problems constituted by interrelated factors [16]. The main steps of weights decision based on AHP are shown as follows:

(1) Establish the hierarchical structure

According to decision objectives and characteristics of multiple criteria problem, all effective factors are divided into three levels in Analytic Hierarchy Process, namely, the target layer, criteria layer and sub-criteria level. The Figure of hierarchical structure is shown as follows:

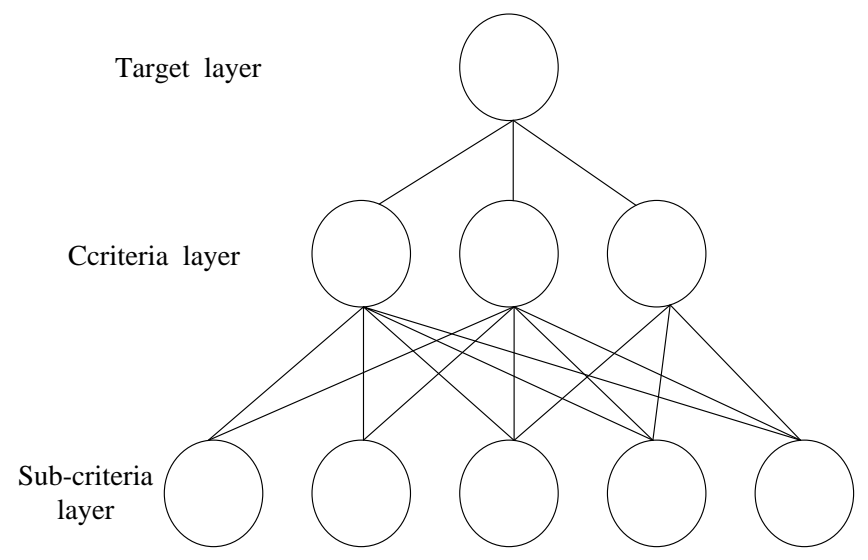

Figure 1. Analytic Hierarchy Process Structure

(2) Structure the judgement matrix

Judgement matrix represents the relative importance of different criteria. In the AHP method, the judgement matrix is the importance comparison of criteria which relate the criterion in the upper layer. Suppose B1,B2, $\cdots$ Bn relate to Ai in the upper level, according to the relative importance of $\mathrm{B} 1, \mathrm{~B} 2, \ldots \mathrm{Bn}$, the judgement matrix are established as follows:

$$
B=\left\{\begin{array}{cccc}
b_{11} & b_{12} & \cdots & b_{1 n} \\
b_{21} & b_{22} & \cdots & b_{2 n} \\
\cdots & \cdots & \cdots & \cdots \\
b_{n 1} & b_{n 2} & \cdots & b_{n n}
\end{array} \mid b_{i j}>0 ; b_{i i}=1 ; b_{i j}=1 / b_{j i} ; \quad(i=1,2, \cdots n)\right.
$$

In which, the 1-9 scale method is always used to determine the judgement matrix. The meaning of 1-9 scale is shown in Table 1. 
Table 1. 1-9 Scale Meaning Table

\begin{tabular}{ll}
\hline bij & The meaning of bij \\
\hline 1 & Bi is as important as $\mathrm{Bj}$ \\
3 & Bi is little more important than $\mathrm{Bj}$ \\
5 & Bi is more important than $\mathrm{Bj}$ \\
7 & Bi is much more important than $\mathrm{Bj}$ \\
9 & Bi is extremely more important than $\mathrm{Bj}$ \\
$2,4,6,8$ & Between the two adjacent levels \\
$1,1 / 2, \ldots, 1 / 9$ & The reciprocals of $1,2, \cdots, 9$ \\
\hline
\end{tabular}

(3) Calculate the local weights and consistency judgement

According to equation (1), the local weight for each element is calculated. In the AHP, the eigenvector of the judgment matrix corresponding to the largest Eigen value is the local weight [17].

In addition, the consistency of the judgment matrix should be tested, so as to make sure the coordination of relative importance between various elements. The ratio of random index $\mathrm{CR}$, which equals to $\mathrm{CI} / \mathrm{RI}$, is the standard of consistency test. Where, $C I=\left(\lambda_{\max }-\mathrm{n}\right) /(\mathrm{n}-1)$. And the values of average random consistency index RI are shown in table 2. Only when the random consistency ratio CR is less than 0.1 , the judgment matrix has satisfactory consistency.

Table 2. Random Index (RI)

\begin{tabular}{lllrrrrrrrr}
\hline Order & 1 & 2 & 3 & 4 & 5 & 6 & 7 & 8 & 9 & 10 \\
\hline RI & 0 & 0 & 0.58 & 0.9 & 1.12 & 1.24 & 1.32 & 1.41 & 1.45 & 1.49 \\
\hline
\end{tabular}

(4) Calculate the overall weight

The overall weight of index is multiplied by its local weights in criteria layer and subcriteria level [18]. What's more, the sum of overall weights of all criteria equals to 1.

\subsection{Formula Method}

In order to improve the accuracy of index weights, the weights result can be obtained based on AHP and formula method. The weight determination based on formula method is simpler than other method, such as Delphi method, interval estimation method, Analytic Network Process and so on. Meanwhile, all these methods are easily influenced by subjective factors. Therefore, in this paper, the weights of criteria are determined based on AHP and Formula method, which is shown as follows:

$$
W_{i}^{\prime}=\left\{\begin{array}{l}
\frac{\sqrt{-2 \ln \left(\frac{2(i-1)}{n}\right)}}{6}\left(1<i \leq \frac{n+1}{2}\right) \\
\frac{1}{2}-\frac{\sqrt{-2 \ln \left(2-\frac{2(i-1)}{n}\right)}}{6}\left(\frac{n+1}{2}<i \leq n\right)
\end{array}\right.
$$

Where, $W_{i}{ }^{\prime}$ and $i \quad i=1,2, \ldots, m(m \leq n)$ denotes the importance of index and index orders respectively. The index orders are determined according to the importance of indexes. The more important indicator is, the smaller the value of $i$ is. And the index weight $W_{i}$ can be obtained through the normalization of $W_{i}$ '.

At last, the final weights of criteria equal to the average of the weights based on AHP and Formula method. 


\subsection{The Comprehensive Evaluation Model based on AHP-formula Method and Gray Clustering Model}

The basic idea of evaluation method based on AHP- Grey Clustering decision model (GCDM) is as follows. First, the evaluation object is divided into several levels according to the relevant national standards; Second, the whitened function of each index for each level is established; Then, using AHP to determine the weight of each index, and substitute the evaluation index values into a collection of various grades to calculate the integrated clustering coefficient. The greater its value is, the degree of compliance belong to this level is the greater [16]. The specific steps are as follows:

(1) Determine the evaluation gray classes

Suppose there are $m$ objects to be evaluated, $n$ evaluation indicators and $p$ different gray types $q(\mathrm{q}=1,2 \ldots, \mathrm{p})$. The value of index $\mathrm{j}$ about object $i$ to be evaluated is $\mathrm{x}_{\mathrm{ij}}(\mathrm{i}=$ $1,2 \ldots, \mathrm{m} ; \mathrm{j}=1,2 \ldots, \mathrm{n})$. Divide the number of grey class $\mathrm{p}$ according to the requirements of assessing; namely, determine the level of evaluation gray class.

(2) Establish the triangular whitening functions

Suppose the range of indicator $j$ is $\left[\mathrm{a}_{1}, \mathrm{a}_{\mathrm{M} 1}\right]$, and divided it into $\left[a_{1}, a_{2}\right], \ldots,\left[a_{k}, a_{k+1}\right], \ldots,\left[a_{M}, a_{M+1}\right]$. When $x=\frac{a_{k}+a_{k+1}}{2}$ the triangular white function belongs to $k$ the gray class equals 1 . Then, the triangular white function of $k$ th gray glass $\mathrm{f}_{\mathrm{j}}^{\mathrm{k}}(\mathrm{x})(\mathrm{j}=1,2, \ldots, \mathrm{n} ; \mathrm{k}=1,2, \ldots, \mathrm{q})$ can be obtained through connecting the point of $\left.\frac{a_{k}+a_{k+1}}{2}, 1\right)$ with the $\left(a_{k-1}, 0\right)$ and $\left(a_{k+2}, 0\right)$. In particular, for the $f_{j}^{1}(x)$ and $f_{j}^{q}(x)$, the range of $x$ should be extended to $\mathrm{a}_{0}, \mathrm{a}_{\mathrm{q}+2}$, respectively [19]. As shown in Figure 2:

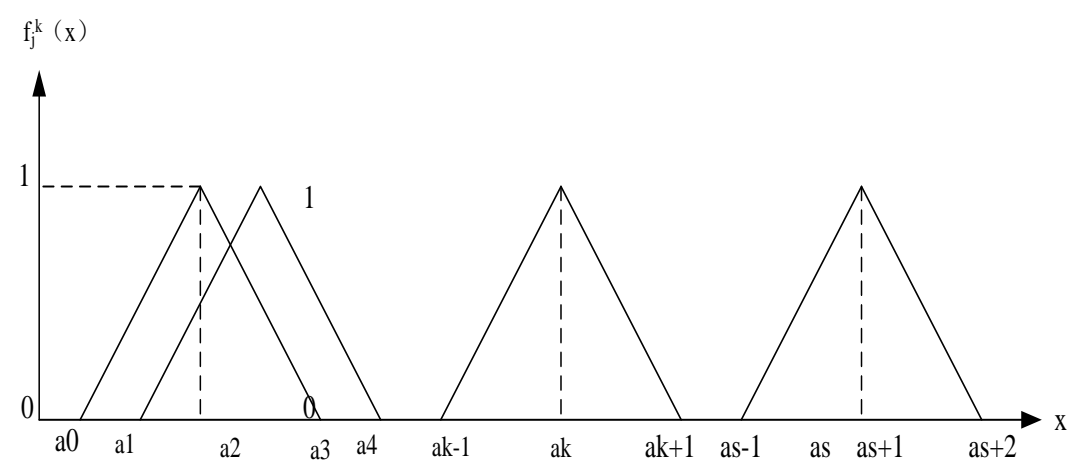

Figure 2. The Triangular White Function

Suppose the actual value of indicator $j$ is $x$, the membership degree $f_{j}^{k}(x)(k=1,2 \ldots, q)$ can be described as follow:

$$
f_{j}^{k}(x)=\left\{\begin{array}{cc}
0 & x \notin\left[a_{k-1}, a_{k+2}\right] \\
\left(x-a_{k-1}\right) /\left(\lambda_{k}-a_{k-1}\right) & x \in\left[a_{k-1}, \lambda_{k}\right] \\
\left(a_{k+2}-x\right) /\left(a_{k+2}-\lambda_{k}\right) & x \in\left[\lambda_{k}, a_{k+2}\right]
\end{array}\right.
$$

Where, $\lambda=\frac{\mathrm{a}_{\mathrm{k}}+\mathrm{a}_{\mathrm{k}+1}}{2}$.

(3) Determine the weights of evaluation indexes

Use the Analytic Hierarchy Process to determine the weight of each index.

(4) Calculate the integrated clustering coefficient

Calculate the integrated clustering coefficient of object $i$ related to the gray class $k[20]$. 


$$
\sigma_{j}{ }^{k}=\sum_{j=1}^{n} \boldsymbol{f}_{j}{ }^{k}\left(\boldsymbol{x}_{i j}\right) * \eta_{j}
$$

Where $f_{j}{ }^{k}\left(\boldsymbol{x}_{i j}\right)$ is the triangular white function of object $i$ related to index $j$ belonging to the gray class $\mathrm{k} ; x_{i j}$ is the value of object $i$ toward index $j$, is the weight of index $j$.

(5) Determine the grey class.

According to $\max _{1 \leq k \leq q}=\left\{\sigma_{j}{ }^{k}\right\}=\sigma_{j}{ }^{k^{*}}$, object ${ }^{i}$ to be evaluated, belongs to gray class $\mathrm{k}^{*}[21]$.

\section{Case Study}

In this section, an evaluation of the social benefits of a natural gas CCHP project will be presented. The natural gas CCHP project is located in city A, which was built in 2012 .

\subsection{Primary Data}

The primary data of the evaluation indicators are quantified by experts scoring through releasing the questionnaires. All scores are among 0-10. Meanwhile, the higher the score is, the better the benefit is. The specific primary data are shown as below:

Table 3. The Primary Data for the Social Benefits Evaluation

\begin{tabular}{|l|l|}
\hline \multicolumn{1}{|c|}{ Indicators } & Primary data \\
\hline Resource saving benefit & 8 \\
\hline Pollutant emission reduction benefits & 7.9 \\
\hline Resources recycling benefits & 5.9 \\
\hline Power grid operation efficiency benefits & 9 \\
\hline Land use benefits & 2.3 \\
\hline Industry development benefits & 7.4 \\
\hline Social employment benefits & 4.5 \\
\hline
\end{tabular}

\subsection{The Evaluation of the Social Benefits for the Project in City $Z$}

(1)Determining the gray classes of evaluation

In order to evaluate the social benefits reasonably, five classes are divided to represents the "very poor", "poor", "moderate", "good", and "very good", respectively. Moreover, the ranges of all glasses are $[1,2),[2,4),[4,6),[6,8),[8,9]$.

(2) Determine the weights of indicators

1) Establish the hierarchy model of indicators and calculate the criteria weights based on AHP

It is a primary work to establish the hierarchy model of indicators when using the AHP method. The index system and index weights based on AHP for the social benefit of natural gas CCHP project is divided into three levels, which is shown in Table 4. 
Table 4. The Weight of Each Criterion based on AHP

\begin{tabular}{|c|c|c|c|c|}
\hline $\begin{array}{c}\text { Objective } \\
\text { layer }\end{array}$ & \multicolumn{2}{|c|}{ Principle layer } & \multicolumn{2}{|l|}{ Scheme layer } \\
\hline \multirow{7}{*}{$\begin{array}{l}\text { The } \\
\text { comprehensive } \\
\text { social benefits } \\
\text { for the natural } \\
\text { gas CCHP } \\
\text { project }\end{array}$} & \multirow{3}{*}{$\begin{array}{l}\text { The natural } \\
\text { environmental } \\
\text { benefits } U_{1}\end{array}$} & \multirow{3}{*}{0.58} & Resource saving benefit $\mathrm{U}_{11}$ & 0.29 \\
\hline & & & $\begin{array}{l}\text { Pollutant emission reduction } \\
\text { benefits } U_{12}\end{array}$ & 0.174 \\
\hline & & & $\begin{array}{l}\text { Resources recycling benefits } \\
U_{13}\end{array}$ & 0.116 \\
\hline & \multirow{4}{*}{$\begin{array}{l}\text { The social } \\
\text { economy } \\
\text { benefits } \mathrm{U}_{2}\end{array}$} & \multirow{4}{*}{0.42} & $\begin{array}{c}\text { Power grid operation efficiency } \\
\text { benefits } U_{21}\end{array}$ & 0.1289 \\
\hline & & & Land use benefits $\mathrm{U}_{22}$ & 0.1176 \\
\hline & & & $\begin{array}{l}\text { Industry development benefits } \\
\qquad U_{23}\end{array}$ & 0.063 \\
\hline & & & Social employment benefits $U_{24}$ & 0.1105 \\
\hline
\end{tabular}

2) Calculate the criteria weights based on Formula method

Table 5. The Weight of Each Criterion

\begin{tabular}{|c|c|c|c|}
\hline & criteria & $\begin{array}{c}\text { Formula } \\
\text { method }\end{array}$ & $\begin{array}{c}\text { Final } \\
\text { criteria } \\
\text { weights }\end{array}$ \\
\hline \multirow{7}{*}{$\begin{array}{l}\text { The } \\
\text { comprehensive } \\
\text { social benefits } \\
\text { for the natural } \\
\text { gas CCHP } \\
\text { project }\end{array}$} & Resource saving benefit $\mathrm{U}_{11}$ & 0.2355 & 0.2628 \\
\hline & Pollutant emission reduction benefits $\mathrm{U}_{12}$ & 0.1300 & 0.1520 \\
\hline & Resources recycling benefits $U_{13}$ & 0.1055 & 0.1108 \\
\hline & Power grid operation efficiency benefits $\mathrm{U}_{21}$ & 0.1758 & 0.1524 \\
\hline & Land use benefits $\mathrm{U}_{22}$ & 0.1531 & 0.1354 \\
\hline & Industry development benefits $\mathrm{U}_{23}$ & 0.1177 & 0.0904 \\
\hline & Social employment benefits $\mathrm{U}_{24}$ & 0.0824 & 0.0965 \\
\hline
\end{tabular}

(3) Construct triangular white functions

Enlarging the range of the $\mathrm{x}$, it is feasible to stretch the border of range to the left or right at 5 and 95 , namely, $\mathrm{a} 0=0.5 ; \mathrm{a} 1=1 ; \mathrm{a} 2=2 ; \mathrm{a} 3=4 ; \mathrm{a} 4=6 ; \mathrm{a} 5=8 ; \mathrm{a} 6=9 ; \mathrm{a} 7=9.5$, so $\lambda 1=1.5 ; \lambda 2=3 ; \lambda 3=5 ; \lambda 4=7 ; \lambda 5=8.5$, the triangular white functions of gray classes are as follows:

$$
\begin{aligned}
f_{j}^{1}(x)=\left\{\begin{array}{cc}
0 & x \notin[0.5,4] \\
\frac{x-0.5}{25} & x \notin[0.5,1.5]
\end{array}\right. \\
f_{j}^{2}(x)=\left\{\begin{array}{cc}
\frac{4-x}{2.5} & x \notin[1.5,4] \\
\frac{x-1}{2} & x \notin[1,3] \\
\frac{6-x}{3} & x \notin[3,6]
\end{array}\right.
\end{aligned}
$$




$$
\begin{aligned}
& \begin{cases}0 & x \notin[2,8]\end{cases} \\
& f_{j}^{3}(x)= \begin{cases}\frac{x-2}{3} & x \notin[2,5]\end{cases} \\
& \frac{8-x}{3} \quad x \notin[5,8] \\
& f_{j}^{4}(x)=\left\{\begin{array}{cc}
0 & x \notin[4,9] \\
\frac{x-4}{3} & x \notin[4,7] \\
\frac{9-x}{2} & x \notin[7,9]
\end{array}\right. \\
& f_{j}^{5}(x)=\left\{\begin{array}{cc}
0 & x \notin[6,9.5] \\
\frac{x-6}{2.5} & x \notin[6,8.5] \\
9.5-x & x \notin[8.5,9.5]
\end{array}\right.
\end{aligned}
$$

(5) Calculate the comprehensive clustering coefficient

Take the actual value of each indicator into the triangular white functions, and calculate the clustering coefficient of each gray class for each criterion.

Table 6. The Clustering Coefficient

\begin{tabular}{|c|c|c|c|c|c|c|}
\hline Indicator & Actual value & $\mathrm{f}_{\mathrm{j}}{ }^{1}(\mathrm{x})$ & $\mathrm{f}_{\mathrm{j}}^{2}(\mathrm{x})$ & $\mathrm{f}_{\mathrm{j}}^{3}(\mathrm{x})$ & $\mathrm{f}_{\mathrm{j}}^{4}(\mathrm{x})$ & $\mathrm{f}_{\mathrm{j}}^{5}(\mathrm{x})$ \\
\hline $\mathrm{U}_{11}$ & 8.0 & 0 & 0 & 0 & 0.5 & 0.8 \\
\hline $\mathrm{U}_{12}$ & 7.9 & 0 & 0 & 0.033 & 0.057 & 0.76 \\
\hline $\mathrm{U}_{13}$ & 5.9 & 0 & 0.033 & 0.7 & 0.633 & 0 \\
\hline $\mathrm{U}_{21}$ & 9.0 & 0 & 0 & 0 & 0 & 0.5 \\
\hline $\mathrm{U}_{22}$ & 2.3 & 0.68 & 0.65 & 0.1 & 0 & 0 \\
\hline $\mathrm{U}_{23}$ & 7.4 & 0 & 0 & 0.2 & 0.8 & 0.56 \\
\hline $\mathrm{U}_{24}$ & 4.5 & 0 & 0.5 & 0.833 & 0.167 & 0 \\
\hline
\end{tabular}

According to the formula of the comprehensive clustering coefficient, the comprehensive clustering coefficients related to each gray class can be calculated, which are shown as follows: 


$$
\begin{aligned}
& \sigma_{j}^{1}=\sum_{j=1}^{8} f_{j}^{1}\left(x_{i j}\right) \times \omega_{j}=0.092038 \\
& \sigma_{j}^{2}=\sum_{j=1}^{8} f_{j}^{2}\left(x_{i j}\right) \times \omega_{j}=0.139587 \\
& \sigma_{j}^{3}=\sum_{j=1}^{8} f_{j}^{3}\left(x_{i j}\right) \times \omega_{j}=0.194489 \\
& \sigma_{j}^{4}=\sum_{j=1}^{8} f_{j}^{4}\left(x_{i j}\right) \times \omega_{j}=0.298531 \\
& \sigma_{j}^{5}=\sum_{j=1}^{8} f_{j}^{5}\left(x_{i j}\right) \times \omega_{j}=0.452491
\end{aligned}
$$

(6) Determine the evaluation glass

According to $\underset{1 \leq k \leq q}{\max }=\left\{\sigma_{j}{ }^{k}\right\}=\sigma_{j}{ }^{k *}$, the evaluation level of the social benefit for this project belongs to "very good".

\section{Conclusions}

Owning to the characteristics of higher energy efficiency and cleaner natural gas, the $\mathrm{CCHP}$ project can reduces pollutant emission, which has a higher natural environment benefits. Meanwhile, it can promote the development of society economy. On the one hand, it promotes the development of related industries. On the other hand, it generates much more job opportunities to the society. What's more, the natural gas CCHP project has an efficient capability of peaking adjustment. Therefore, in this paper, a comprehensive evaluation framework is proposed. The established index system reflects the social benefit from the natural environment social economy. Moreover, the comprehensive evaluation model is established based on AHP-Formula method and GCDM model. At last, an empirical analysis of a project in city A is presented, which shows that the social benefits of this project is "very good", in which the feasibility of this model is proved.

\section{Acknowledgments}

This study is supported by the State grid corporation of science and technology project (Contract number: SGHB0000DKJS1400116), the Humanity and Social Science project of the Ministry of Education of China (Project number: 11YJA790217) and the National Natural Science Foundation of China (Project number: 71373076).

\section{References}

[1] S. Sepehr, Z. Masoud and G. Maziar, "Optimal design of gas turbine CHP plant with preheater and HRSG”, International Journal of Energy Research, vol. 33, no. 8, (2009), pp. 766-777.

[2] X. Huang, "The CCHP project configuration and the optimization of operation strategy", Power engineering, vol. 26, no. 6, (2006), pp. 894-898.

[3] C. Li and X. Huang, "The effect of load structure to the CCHP project", Thermal power engineering, vol. 23, no. 6, (2008), pp. 606-610.

[4] T.-M. Tveit, T. Savola, A. Gebremedhin, et al., "Multi-period MINLP model for optimising operation and structural changes to CHP plants in district heating networks with long-term thermal storage", Energy Conversion and Management, vol. 50, no. 3, (2009), pp. 639-647. 
[5] R. Yokoyama and K. Ito, "Optimal operational planning of cogeneration systems with thermal storage by the decomposition method", Transactions of the ASME. Journal of Energy Resources Technology, vol. 117, no. 4, (1995), pp. 337-342.

[6] H. Zhao, J. Holst and L. Arvastson, "Optimal operation of coproduction with storage”, Energy, vol. 23, no. 10, (1998), pp. 859-866.

[7] L. Duan and S. Han, "The optimization of system operation mode", Thermal science and technology, vol. 6, no. 2, (2007), pp. 95-100.

[8] X. Q. Kong, R. Z. Wang, Y. Li, et al., "Optimal operation of a micro-combined cooling, heating and power system driven by a gas engine", Energy Conversion and Management, vol. 50, no. 3, (2009), pp. 530-538.

[9] Z. Wang, "The optimization of the micro gas CCHP project", North China Electric Power University, (2006).

[10] D. W. Wu and R. Z. Wang, "Combined cooling, heating and power: a review", progress in energy and combustion science, vol. 32, no. 5, (2006), pp. 459-495.

[11] J. Deng, R. Z. Wang and G. Y. Han, "A review of thermally activated cooling technologies for combined cooling, heating and power systems", Progress in Energy and Combustion Science, vol. 37, no. 2, (2011), pp. 172-203.

[12] Y. Huangfu, J. Y. Wu, R. Z. Wang, et al., "Evaluation and analysis of novel micro-scale combined cooling, heating and power (MCCHP) system", Energy Conversion and Management, vol. 48, no. 5, (2007), pp. 1703-1709.

[13] S. Li and J. Y. Wu, "Theoretical research of a silica gel-water adsorption chiller in a micro combined cooling, heating and power (CCHP) system”, Applied Energy, vol. 86, no. 6, (2009), pp. 958-967.

[14] X. Q. Kong, R. Z. Wang, Y. Li, et al., "Optimal operation of a micro-combined cooling, heating and power system driven by a gas engine”, Energy Conversion and Management, vol. 50, no. 3, (2009), pp. 530-538.

[15] L. Fu, X. L. Zhao, S. G. Zhang, et al., "Laboratory research on combined cooling, heating and power (CCHP) systems", Energy Conversion and Management, vol. 50, no. 4, (2009), pp. 977-982.

[16] M. P. Amiri, "Project selection for oil-fields development by using the AHP and fuzzy TOPSIS methods", Expert Systems with Applications, vol. 37, (2010), pp. 6218-24.

[17] C. Y. Maggie, V. M. Tama and R. Tummala, "An application of the AHP in vendor selection of a telecommunications system”, Omega, vol. 29, (2001), pp. 171-182.

[18] L.-L. Li and L.-X. Liu, "The Comprehensive Evaluation of Smart Distribution Grid Based on Cloud Model”, Energy Procedia, vol. 17, (2012), pp. 96-102.

[19] T. Wang, J. Zhang, L.-L. Wu, et al., "Comprehensive assessment on air quality of urban road environment based on improved gray-clustering method", Environmental Engineering, vol. 27, no. 2, (2009), pp. 38-41.

[20] Y.-Q. Ma, "Assessment of city atmospheric environment quality by improved gray cluster relation analysis method", Journal of Shandong polytechnic university, vol. 27, no. 2, (2013), pp. 63-65.

[21] H.-R. Zhao and N.-N. Li, "Comprehensive evaluation of urban power network planning risk based on AHP- gray triangle whiten function”, Shanxi electric power, no. 10, (2013), pp. 14-18.

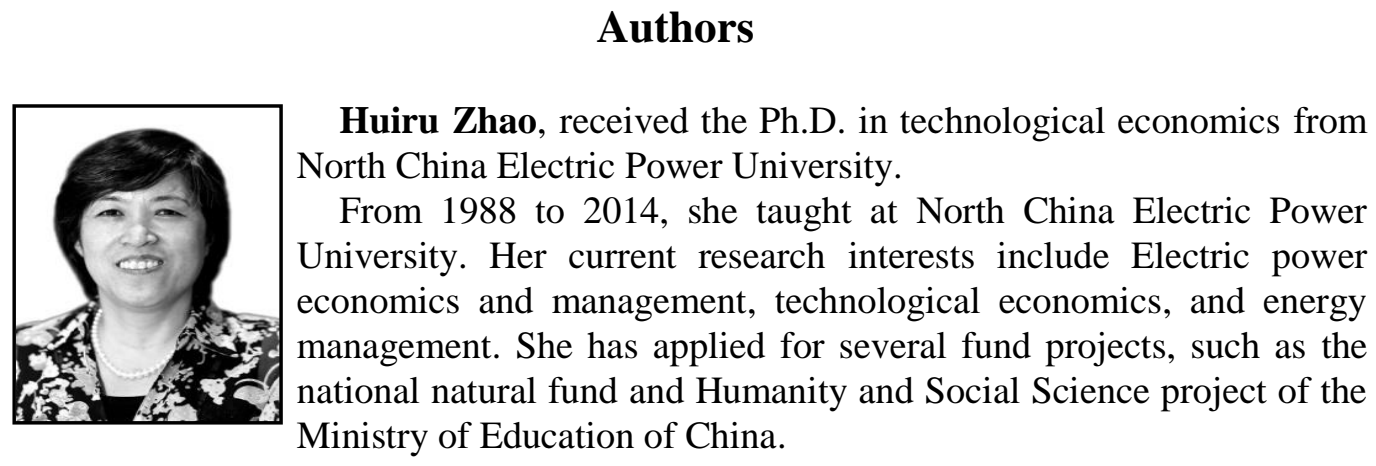




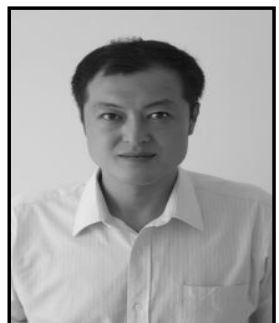

Zhao Ma, received the master degree in business administration from Northeast University of finance. And he is reading for the Ph.D. in energy management in North China Electric Power University.

His current research interests include Electric power economics and management, renewable energy sources, and energy management.

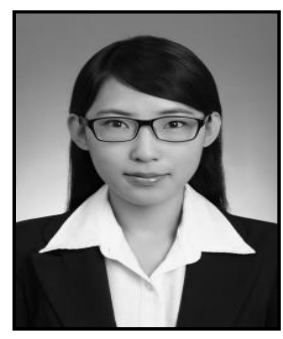

Nana Li, received the master degree in technological economics from North China Electric Power University. And she is reading for the Ph.D. in energy management in North China Electric Power University.

From 2012 to 2014, she studied at North China Electric Power University. Her current research interests include Electric power economics and management, technological economics, and energy management. 
International Journal of Hybrid Information Technology Vol.8, No.11 (2015) 